(2) Open Access Full Text Article

REVIEW

\title{
Spotlight on valsartan-sacubitril fixed-dose combination for heart failure: the evidence to date
}

This article was published in the following Dove Press journal:

Drug Design, Development and Therapy

9 May 2016

Number of times this article has been viewed

José Fernando Vilela-Martin

Internal Medicine Department, São José do Rio Preto State Medical School (FAMERP), São José do Rio Preto, Brazil
Correspondence: José Fernando Vilela-Martin

Internal Medicine Department, São José do Rio Preto State Medical School (FAMERP), 5416 Avenida Brigadeiro Faria Lima, São José do Rio Preto, São Paulo I5090-000, Brazil

Tel/fax +55 I7 320। 5727

Email vilelamartin@uol.com.br
Abstract: Heart failure is a global problem with elevated prevalence, and it is associated with substantial cardiovascular morbidity and mortality. Treating heart-failure patients has been a very challenging task. This review highlights the main pharmacological developments in the field of heart failure with reduced ejection fraction, giving emphasis to a drug that has a dual-acting inhibition of the neprilysin and renin-angiotensin-aldosterone system. Neprilysin is an enzyme that participates in the breakdown of biologically active natriuretic peptides and several other vasoactive compounds. The inhibition of neprilysin has been a therapeutic target for several drugs tested in cardiovascular disease, mainly for heart failure and/or hypertension. However, side effects and a lack of efficacy led to discontinuation of their development. LCZ696 is a first-in-class neprilysin- and angiotensin-receptor inhibitor that has been developed for use in heart failure. This drug is composed of two molecular moieties in a single crystalline complex: a neprilysin-inhibitor prodrug (sacubitril) and the angiotensin-receptor blocker (valsartan). The PARADIGM-HF trial demonstrated that this drug was superior to an angiotensin-converting enzyme inhibitor (enalapril) in reducing mortality in patients with heart failure with reduced ejection fraction. The ability to block the angiotensin receptor and augment the endogenous natriuretic peptide system provides a distinctive mechanism of action in cardiovascular disease.

Keywords: heart failure, vasopeptidase, natriuretic peptides, neprilysin, sacubitril, valsartan

\section{Introduction}

\section{The impact of heart failure in the global context}

Cardiovascular disease (CVD) is the major cause of mortality in developed and many developing countries, accounting for about $30 \%$ of the overall mortality. ${ }^{1}$ Early mortality rates associated with CVD, including those related to acute coronary syndromes, valvular and congenital heart disease, stroke, and hypertension, have decreased substantially., ${ }^{2,3}$ A study of the decrease in US deaths attributable to coronary heart disease from 1980 to 2000 suggests that $\sim 47 \%$ of the decrease was attributable to increased use of evidence-based medical therapies for secondary prevention and $44 \%$ to changes in risk factors in the population attributable to lifestyle and environmental changes. ${ }^{2}$ However, a great number of patients with these disorders progress with myocardial damage and consequently chronic heart disease, in spite of their lives having been prolonged. Hypertension, which is highly prevalent in the population, is one of the main factors associated with the elevated number of cardiovascular events. Therefore, an increasing number of individuals are exposed to greater risk of subsequently developing heart failure (HF).

HF is a global problem, with an estimated 38 million patients diagnosed worldwide. ${ }^{1,3-6}$ The Global Burden of Disease 2010 study reported that from 1990 to 2010, ischemic heart disease, one source of myocardial damage, was the most common cause of death $\mathrm{BY}$
hereby accept the Terms. Non-commercial uses of the work are permitted without any further permission from Dove Medical Press Limited, provided the work is properly attributed. For permission for commercial use of this work, please see paragraphs 4.2 and 5 of our Terms (https://www.dovepress.com/terms.php). 
worldwide. ${ }^{3,4}$ Other very common conditions associated with $\mathrm{HF}$ are hypertension and diabetes. HF is now becoming more common, even in low-income and medium-income countries, because a high proportion of the population has a lifestyle that leads to obesity, diabetes mellitus, and in particular hypertension (75\% of HF cases have antecedent hypertension). These are well-known risk factors for the development of HF. ${ }^{5,6}$

On the basis of data from the National Health and Nutrition Examination Survey of 2009-2012, an estimated 5.7 million Americans over 20 years old have HF. Projections show that the prevalence of HF will increase in the US to $46 \%$ by 2030 , with more than 8 million people aged 18 years and over with $\mathrm{HF}^{7}$ There are 915,000 new HF cases annually in the US, with African-Americans having the highest risk of developing the disease because of the greater prevalence of hypertension, diabetes mellitus, and low socioeconomic status in this ethnic group. ${ }^{1,8}$ A $50 \%$ increase in the number of new cases of HF is also estimated, mainly due to the aging population. $^{9-11}$

HF occurs most commonly in elderly people: it is the most common diagnosis at hospital admission in patients aged 65 years and older. Every year, about 1 million hospital admissions occur for HF in the US, with a similar number occurring in Europe. ${ }^{1,9,10}$ In patients aged over 65 years in the US, the 30-day mean hospital-readmission rate is around $30 \%,{ }^{9}$ with $83 \%$ of patients hospitalized at least once and $43 \%$ hospitalized at least four times. ${ }^{12}$ In developing countries, such as Brazil, HF is responsible for $20 \%$ of the total patients admitted to hospital with CVD. ${ }^{13}$

Treating HF individuals is a very challenging task. The art of forming a diagnosis, staging the disease, and establishing an adequate drug association for the patient is crucial for clinical benefits. From the 1990s to the beginning of the 21 st century, neurohormonal blockade has comprised the mainstay of therapy. ${ }^{14-19}$ The activation of neurohormonal pathways, such as the renin-angiotensin-aldosterone system (RAAS) and the sympathetic nervous system (SNS), is very important in the pathophysiology of HF. The inhibition of these pathways was a breakthrough in the treatment of HF. The importance of the RAAS is shown by the results of its blockade using ACE inhibitors (ACEIs), angiotensinreceptor blockers (ARBs) and mineralocorticoid-receptor antagonists. ${ }^{14-17}$ In turn, the beneficial effects of $\beta$-blockers suggest that the SNS has a role in HF ${ }^{18-21}$ Although survival after the diagnosis and treatment of HF has improved over time, especially in patients with reduced ejection fraction (EF), many patients now experience a more prolonged course, resulting in increases in the prevalence of the problem in the population and the economic burden on the health care system. ${ }^{1,22-24}$ Even so, the death rate remains high: $>50 \%$ of people diagnosed with HF will die within 5 years. ${ }^{1,24}$ The number of deaths by any cause attributable to HF was approximately as high in $1995(287,000)$ as it was in $2011(284,000) .{ }^{1}$ In patients aged over 65 years in the US, the 30-day inpatient-mortality rate for patients admitted to hospital with HF is fairly constant at about $11 \%$, with similar results in Europe. ${ }^{25,26}$

The 5-year survival rate for HF is worse than it is for most cancers, and the annual cost of care for HF in the US has been estimated to exceed $\$ 30$ billion. ${ }^{7,27}$ Projections show that by 2030 , the total cost of HF will be almost $127 \%$ higher than 2012: at $\$ 69.7$ billion. This equals $\sim \$ 244$ for every American adult. ${ }^{7} \mathrm{HF}$ is a particular threat in middleincome and low-income countries, where the adjusted hazard ratios for case fatality are 2.61 and 3.72, using high-income countries as the referent. ${ }^{28}$

Evidence shows that the use of $\beta$-blockers and mineralocorticoid-receptor antagonists added to ACEIs results in incremental decreases in the risk of death of $30 \%-35 \%$ and $22 \%-30 \%$, respectively. ${ }^{18-20}$ Despite this, much study is still needed to improve our understanding of the pathophysiology of HF and to develop new approaches to prevent or improve the care of patients with this lethal condition. Research on $\mathrm{HF}$ is now quite dynamic worldwide, and many areas are being explored with the discovery of new pharmacological options. Therefore, this article reviews the physiology of the natriuretic peptide (NP) system. It also considers how novel therapeutic agents that enhance NP levels, in particular those that simultaneously suppress the RAAS, may represent a new opportunity in the treatment of HF. Finally, it also discusses the PARADIGM-HF trial ${ }^{29}$ and the implications it may have on the care of patients with chronic HF.

\section{Neutral endopeptidase: a new target for cardiovascular disease treatment}

NPs constitute a family of similar, but genetically distinct peptides, including atrial NP (ANP), brain NP (BNP), and C-type NP (CNP). ${ }^{30-33}$ ANP and BNP exert their physiological actions through NP receptors type A (NPR-A) and type B (NPR-B), which are coupled to and activate guanylyl cyclase A. This increases the intracellular concentrations of the second messenger, cyclic guanosine $3^{\prime}, 5^{\prime}$-monophosphate (cGMP), known to be the active mediator of biologic effects that include vasodilation, natriuresis, diuresis, inhibition 

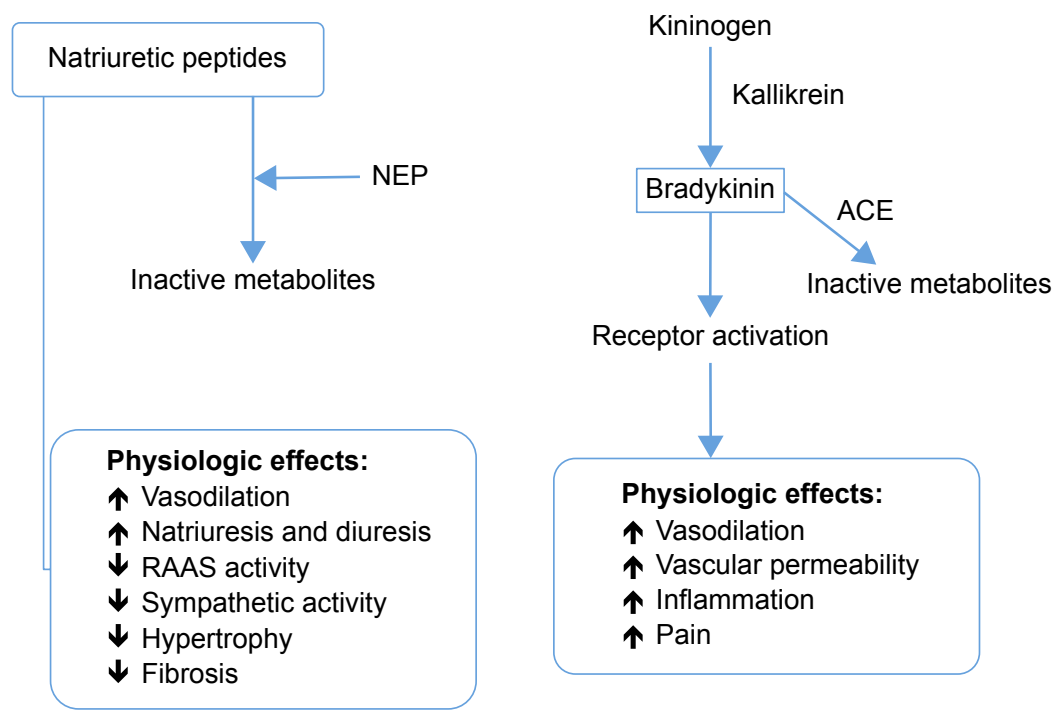

Figure I Schematic of natriuretic peptides and bradykinin and their physiological effects.

Abbreviations: ACE, angiotensin-converting enzyme; NEP, neprilysin; RAAS, renin-angiotensin-aldosterone system.

of the RAAS, endothelin, and vasopressin, and lipid mobilization. ${ }^{34-36}$ Moreover, it reduces sympathetic drive and has antiproliferative and antihypertrophic effects. ${ }^{34-36}$ Distension of the atria and ventricles, as occurs in ventricular dysfunction and HF, results in significant increases in the expression of NPs, particularly of ANP and BNP, as a compensatory response.

On the other hand, NPs have a short half-life in the circulation, with neprilysin (neutral endopeptidase 24.11 [NEP]) being the main enzyme that degrades them. ${ }^{37}$ Therefore, NEP inhibitors would augment active NPs, increasing the generation of myocardial cGMP, which would improve myocardial relaxation and reduce hypertrophy. Moreover, neprilysin inhibitions should protect NPs and protect against the bradykinin catabolic process, and thus would shift the balance of endogenous hormonal factors from a vasoconstrictive, sodium-retaining, and hypertrophic state toward a more vasodilator, natriuretic, and cardioprotective condition, and hence they were expected to be effective in the management of hypertension and HF. ${ }^{38}$ However, the beneficial effects in patients were modest, and NEP inhibition alone did not cause clinically meaningful reductions in blood pressure. ${ }^{39}$ In addition to increasing the concentration of circulating NPs, NEP inhibitors were found to elevate the concentrations of two other circulating vasoconstrictor agents - angiotensin II and endothelin 1 - whose breakdown is dependent on NEP. ${ }^{40-42}$ These two opposing actions, ie, inhibition of the degradation of both vasoconstrictor and vasodilator peptides, neutralized the effects of each other, and as a consequence NEP inhibitors alone had little effect on blood pressure or HF. ${ }^{43,44}$
Figure 1 shows a schematic of NPs and bradykinin and the physiological effects of both.

\section{Vasopeptidase inhibition}

As hitherto described, elevations of circulating angiotensin II due to NEP inhibitors neutralize vasodilator and natriuretic actions. Therefore, it would be interesting to ascertain whether the clinical benefits of NEP inhibition might be enhanced by the concomitant blockade of the RAAS. This concept was the basis for a new drug class known as vasopeptidase inhibitors, which simultaneously inhibit two key enzymes involved in the regulation of cardiovascular function: NEP and ACE. These inhibitors reduce vasoconstriction and enhance vasodilatation, reducing vascular tone and lowering blood pressure. ${ }^{45}$ Therefore, the initial vasopeptidase inhibitors had a dual mechanism of action, acting as neprilysin inhibitors and ACEIs. Figure 2 shows a schematic of the mechanism of action of neprilysin and an ACEI (omapatrilat).

Omapatrilat, the most extensively evaluated of such agents, demonstrated its capacity to inhibit the pressor response to angiotensin I in rats and monkeys. Moreover, omapatrilat potentiated the natriuretic, cGMP, and ANP excretory responses to exogenous atrial NP in monkeys. ${ }^{46}$ Omapatrilat also lowered mean arterial blood pressure at 24 hours in some kinds of experimental hypertension (low renin, normal renin, and high renin).$^{47}$ In healthy individuals, omapatrilat increased urinary ANP and cGMP, indicating NEP inhibition, and increased plasma renin activity, indicating a response to $\mathrm{ACE}$ inhibition. ${ }^{48}$ In hypertensive patients, 


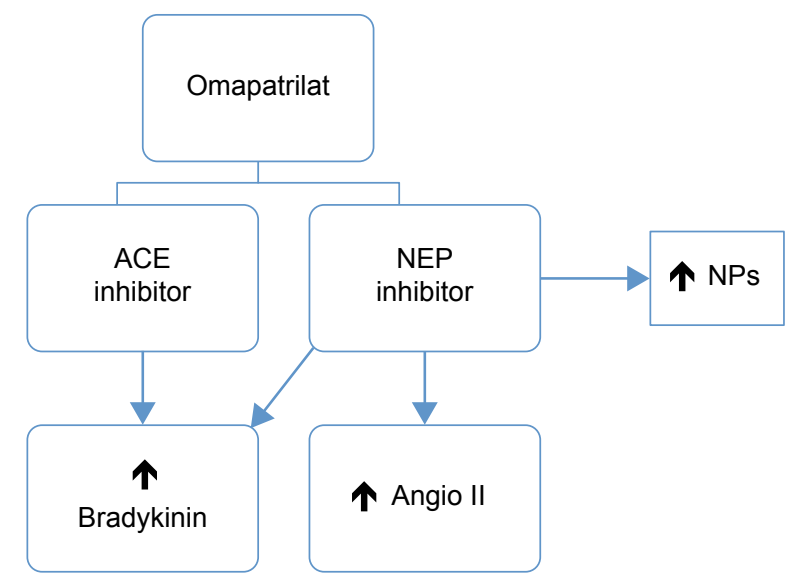

Figure 2 Schematic of action mechanism of NEP and ACE inhibitors (omapatrilat). Abbreviations: NEP, neprilysin; NPs, natriuretic peptides; Angio II, angiotensin II; $\mathrm{ACE}$, angiotensin-converting enzyme.

blood pressure-lowering and vasculoprotective effects were greater than for other therapeutic classes, including ACEIs and calcium-channel blockers. ${ }^{49-53}$ However, some studies showed that angioedema occurred more frequently with omapatrilat than with comparators..$^{50,51}$ The increased incidence of this potentially life-threatening complication is likely due to concomitant inhibition of three enzymes (ACE, aminopeptidase $\mathrm{P}$, and NEP) that participate in the breakdown of bradykinin (the putative mediator of angioedema induced by ACEIs). ${ }^{53}$ Bradykinin is not only a vasodilator but also enhances prostaglandin concentrations and increases vascular permeability and fluid extravasation. ${ }^{54}$ The initial question that made omapatrilat an attractive drug became a "double-edged sword". ${ }^{55,56}$ Due to increased angioedema, the approval of omapatrilat and of further clinical research on the class of vasopeptidase inhibitors was halted.

\section{Novel dual-acting inhibitor of the neprilysin and angiotensin II receptor}

Nowadays, LCZ696, a novel dual-acting inhibitor of neprilysin (sacubitril) and the angiotensin II receptor (valsartan) was designed to minimize the risk of serious angioedema. ${ }^{57,58}$ ARBs have a lower risk of angioedema than ACEIs, probably because of their neutral effect on metallopeptidases involved in the breakdown of bradykinin. ${ }^{59}$ This new drug class concurrently inhibits NEP and blocks angiotensin II receptors, thereby offering the cardioprotective benefits of vasopeptidase inhibitors without the increased risk of angioedema (Figure 3).

LCZ696 (Novartis International AG, Basel, Switzerland) is the first drug with a dual-acting ARB and neprilysin

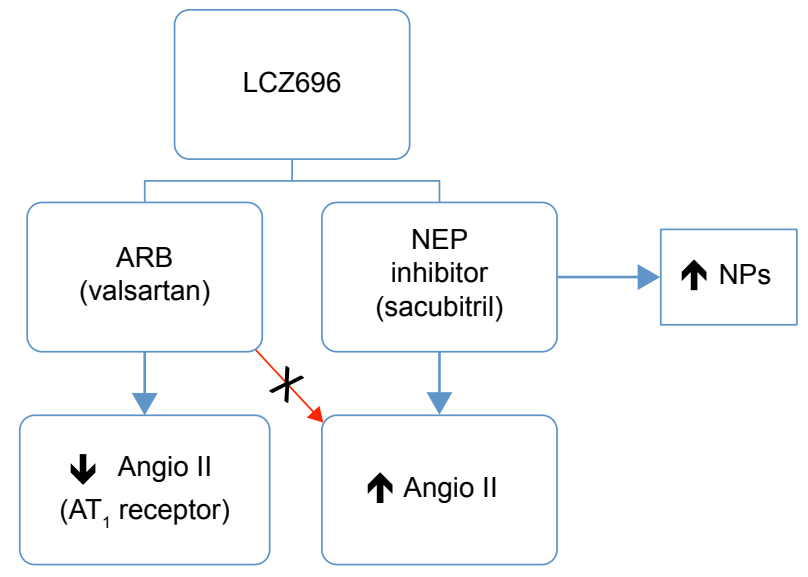

Figure 3 Schematic of action mechanism of NEP (sacubitril) and ARB (valsartan) inhibitors in heart failure.

Abbreviations: ARB, angiotensin-receptor blocker; NEP, neprilysin; NPs, natriuretic peptides; Angio II, angiotensin II.

inhibitor in a single molecule - angiotensin II-receptor blockade via its valsartan molecular moiety, ${ }^{60}$ and neprilysin inhibition via its prodrug AHU377 molecular moiety which is metabolized to the active NEP inhibitor LBQ657 by enzymatic cleavage of its ethyl ester. ${ }^{61}$ The molecular structure of LCZ696, consisting of trisodium (3-[\{1S,3R $\}-1-$ biphenyl-4-ylmethyl-3-ethoxycarbonyl-1-butylcarbamoyl] propionate-[S]-3'-methyl-2'-[pentanoyl $\left\{2^{\prime \prime}\right.$-(tetrazol-5-ylate) biphenyl 4'ylmethyl $\}$ amino]butyrate) hemipentahydrate, was established by X-ray crystallographic techniques. ${ }^{57}$ This drug is also known as angiotensin-receptor and neprilysin inhibitor (ARNI).

\section{Spotlight on sacubitril-valsartan for heart failure in the PARADIGM-HF trial}

As has been described for more than two decades, RAAS blockers (particularly ACEIs and mineralocorticoid-receptor antagonists) and $\beta$-blockers have been the pharmacologic treatment that changed the natural history of HF with reduced EF (HFrEF). ${ }^{14-21}$ Now, the new product combination of the neprilysin inhibitor sacubitril with the ARB valsartan represents an attempt to further improve the bad prognosis of $\mathrm{HF}$, reducing the risk of cardiovascular death and hospitalization rate linked to HF. Sacubitril was the first neprilysin inhibitor to become available in the US, and the sacubitrilvalsartan (sacubitril $97 \mathrm{mg}$, valsartan $103 \mathrm{mg}$ ) association was approved by the US Food and Drug Administration in July 2015 for the treatment of patients with New York Heart Association class II-IV HF and reduced EF based on a double-blind trial: the PARADIGM-HF study. ${ }^{29}$ Figure 4 


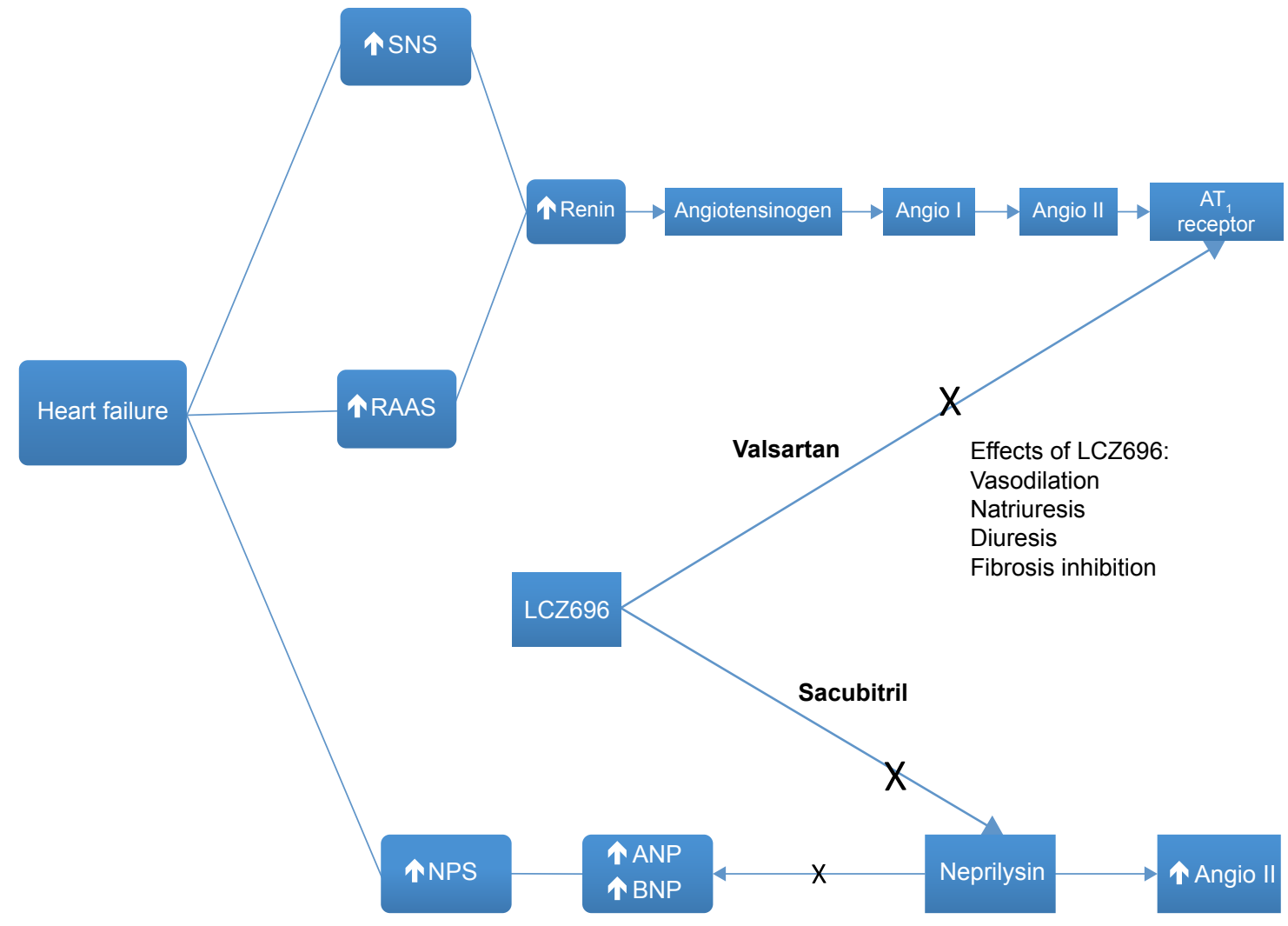

Figure 4 The central role of LCZ696 in the dual inhibition of the RAAS and of neprilysin.

Notes: Heart failure with reduced ejection fraction (HFrEF) activates both the SNS and the RAAS, which act in the release of renin. Renin acts on angiotensinogen to produce Angio I. ACE catalyzes the formation of Angio II, which acts on the AT, receptor, whose physiological actions include the release of aldosterone, besides vasoconstriction and sodium retention. The HFrEF also activates the NPS with release of ANP and BNP, whose physiological actions result in vasodilation, natriuresis, diuresis, and fibrosis inhibition. ANP also blocks the release of renin. On the other hand, neprilysin breaks down ANP. The LCZ696 has two components: an angiotensin-receptor blocker (valsartan), which blocks activation of RAAS; and a neprilysin inhibitor (sacubitril), which preserves ANP. These actions produce beneficial effects on vasodilation, natriuresis, diuresis, and fibrosis inhibition.

Abbreviations: SNS, sympathetic nervous system; RAAS, renin-angiotensin-aldosterone system; NPS, natriuretic peptide system; Angio I, angiotensin I; Angio II, angiotensin II; ANP, atrial natriuretic peptide; BNP, brain natriuretic peptide.

shows the central role of LCZ696 (sacubitril-valsartan) in the dual inhibition of the RAAS and of NEP.

The PARADIGM-HF trial was a high-quality randomized clinical Phase III study of the sacubitril-valsartan combination (LCZ696) that focused on the key outcomes of mortality and HF-related hospitalization. This trial evaluated a total of 8,442 patients (mean age 63.8 years, $78.2 \%$ male) $-4,187$ patients taking the combination and 4,212 taking enalapril with reduced EF ( $\leq 35 \%)$ and New York Heart Association class II-IV HF symptoms. Participants were randomly assigned to sacubitril-valsartan (200 mg twice daily) or enalapril (10 $\mathrm{mg}$ twice daily), in addition to other recommended therapy. Prior to randomization, patients underwent singleblind run-in treatment with enalapril (median duration of treatment 15 days) followed by sacubitril-valsartan (median duration of treatment 29 days) to ensure tolerability. Of the 10,513 patients initially enrolled, 2,079 (19.8\%) withdrew from the study during the run-in phase, 1,138 of whom $(10.8 \%)$ withdrew due to intolerance to treatment; similar proportions withdrew while on run-in treatment with enalapril and sacubitril-valsartan. More than $80 \%$ of the patients in each arm were taking diuretics as background therapy, and $93 \%$ were taking $\beta$-blockers. In the sacubitril-valsartan arm, $54.2 \%$ of patients received a mineralocorticoid antagonist, as did $57 \%$ of the controls. About $30 \%$ of all patients were also taking digitalis. ${ }^{29}$

After a median duration of 27 months of follow-up, the trial was interrupted, because the prespecified boundary for benefit (one-sided $P<0.001$ for reduction in both cardiovascular death and the composite of cardiovascular death and first hospitalization for worsening HF) had been crossed. In the PARADIGM-HF trial, the primary composite end point of death from cardiovascular causes or first hospitalization for worsening HF occurred in $21.8 \%$ of the sacubitril-valsartan group and $26.5 \%$ of the enalapril group (hazard ratio 0.80 , $95 \%$ confidence interval $0.73-0.87 ; P<0.001)$. In this study, the numbers needed to treat to prevent one primary composite event (cardiovascular death or first hospitalization for 
chronic HF) and one cardiovascular death were 21 and 32, respectively. The combination significantly reduced the risk of first hospitalization for worsening HF (12.8\% vs $15.6 \%$, $P<0.001)$, death from cardiovascular causes $(13.3 \%$ vs $16.5 \%, P<0.001)$, and all-cause mortality (17.0\% vs $19.8 \%$, $P<0.001){ }^{29}$

Sacubitril-valsartan had higher reported rates of hypotension and lower rates of cough and renal impairment relative to enalapril. Discontinuation of study medication owing to an adverse event was less frequent among patients in the sacubitril-valsartan group ( $10.7 \%$ vs $12.3 \%, P=0.03)$. Nineteen patients $(0.5 \%)$ in the sacubitril-valsartan group and ten patients $(0.2 \%)$ in the enalapril group experienced angioedema $(P=0.13) .{ }^{29}$

\section{Is PARADIGM-HF exempt from criticism?}

In PARADIGM-HF, the authors declared that their results were applicable to a broad spectrum of patients with HF, including those currently taking an ACEI or ARB or who were likely to be able to take such an agent without having unacceptable side effects, but we have some doubts and considerations about this conclusion.

Firstly, this study had a run-in phase, ie, before patients were randomized, both treatments were tried, and only patients that tolerated the treatment participated in the study. Therefore, the results presented were from the patients selected for tolerating the drug, a condition that may reduce the external validity of the study's safety. In relation to safety, what would the result be in a representative sample of a real-world population?

Secondly, which stable patients should be switched from using RAAS inhibitors to the sacubitril-valsartan combination? Unlike clinical practice, every trial patient underwent a controlled run-in period during which tolerability was carefully assessed. Despite the exclusion of a large number of potential study candidates, symptomatic hypotension remained higher in the sacubitril-valsartan group. This suggests that patients with borderline blood pressure, hypotensive individuals, or those tolerating less than recommended doses of vasodilators may encounter difficulties with the sacubitril-valsartan association. The authors stated that because of its greater vasodilator effects, treatment with LCZ696 was associated with a higher rate of symptomatic hypotension, but there was no increase in the rate of discontinuation due to possible hypotension-related adverse effects. Although the greater hypotensive effect of LCZ696 might impair renal perfusion, clinically important increases in the serum creatinine level and discontinuation of the study drug because of renal impairment were less frequent in the LCZ696 group than in the enalapril group. ${ }^{29}$ In addition, the authors said that the effects of LCZ696 on renal function were consistent with the effects observed in experimental studies ${ }^{62}$ and with findings in earlier trials of omapatrilat. . $^{51,52}$

Finally, the target dose of enalapril in the control group was $20 \mathrm{mg}$ /day. This dose was proportionally lower than the valsartan dose. The European and American guidelines recommend that the target enalapril dosage for treating HF is 10-20 mg twice daily, and the dose of enalapril in PARADIGM-HF was half the maximal approved dosage. ${ }^{63,64}$ On the other hand, in the PARADIGM-HF trial, sacubitrilvalsartan twice daily reduced the incidence of cardiovascular death by $19 \%$ compared with enalapril $10 \mathrm{mg}$ twice daily (the rates were $16.5 \%$ and $13.3 \%$, respectively). ${ }^{29}$ Besides, the sacubitril-valsartan combination lowered mean systolic blood pressure $3.2 \pm 0.4 \mathrm{mmHg}$ more than enalapril, ${ }^{29,65}$ a fact that may account for much of this benefit. Previous data showed that a $2 \mathrm{mmHg}$ decrease in systolic blood pressure reduced the risk of cardiovascular death by $7 \%$ in middleaged adults. ${ }^{66}$ That study did not involve HF patients, but if its results are remotely applicable to PARADIGM-HF, a $3.2 \mathrm{mmHg}$ reduction in systolic blood pressure might be expected to reduce the rate of cardiovascular deaths by $10 \%-11 \%{ }^{67}$

Therefore, would a sacubitril-valsartan combination be superior to enalapril if the maximal dose of enalapril were compared to the maximal dose of sacubitril-valsartan? Would sacubitril-valsartan be superior to enalapril if blood pressure were lowered comparably between the two groups?

In relation to first question, the authors said that the choice of an active comparator was based upon the SOLVD trial, which was a pivotal ACEI mortality/morbidity study in a broad spectrum of patients with HFrEF. ${ }^{15}$ In the SOLVD trial, the target dose of enalapril was $10 \mathrm{mg}$ twice daily and the mean daily prescribed dose in patients taking enalapril was $16.6 \mathrm{mg} /$ day. The same target dose of enalapril was used in several other HF trials, in which the mean daily dose of enalapril was between 15 and $18 \mathrm{mg} .{ }^{14,68-73}$ Two trials, which had higher target doses $(20 \mathrm{mg}$ twice daily and $30 \mathrm{mg}$ twice daily), achieved only slightly greater average doses (18.4 and $19.3 \mathrm{mg}$, respectively), with less than $50 \%$ of patients titrated to target. ${ }^{14,71}$ Therefore, the authors considered that "... from a regulatory perspective, the 'gold standard' comparator for LCZ696 is enalapril $10 \mathrm{mg}$ bid. [twice daily], the most tested ACE inhibitor in HFrEF", 
and they anticipated that achieving a similar average dose to that attained in the SOLVD trial would be required. ${ }^{74}$ Moreover, this dosage of enalapril was chosen based on its survival benefit in previous trials. However, this still raises the question of whether the benefit seen in the sacubitrilvalsartan group was due to greater inhibition of the RAAS rather than to the new drug. ${ }^{75}$ Another important point is that the fixed dose of $20 \mathrm{mg}$ a day of enalapril used in the study is not the same as a mean dose of $20 \mathrm{mg}$ a day, which results from individualization according to the patient, using higher doses in some and lower doses in others. A mean dose of $20 \mathrm{mg}$ a day is probably more effective than a fixed dose of $20 \mathrm{mg}$ a day. ${ }^{76}$

To address the second point, it seems that the sacubitrilvalsartan group had better treatment than the control group. This can be suggested by a lower blood pressure level in the LCZ696 group compared to the control group, maybe evidencing a greater blockade of the RAAS (greater dose of valsartan vs enalapril), a fact previously highlighted. ${ }^{77}$ On the other hand, the addition of the NEP inhibition in this group resulted in greater vasodilator effects, a situation evidenced by a higher chance of symptomatic hypotension in the sacubitril-valsartan group. This could be a limitation of the study, although the authors wrote that the benefit of LCZ696 over enalapril was not explained by the small difference in blood pressure, because when the difference in the blood pressure between the two groups was examined as a time-dependent covariate, it was not a significant predictor of the benefit of sacubitril-valsartan. ${ }^{29}$

\section{Progression of heart failure and evaluation of subgroups in PARADIGM-HF}

The PARADIGM-HF investigators reported that among the survivors in the study, those who received sacubitrilvalsartan presented better outcomes in terms of a number of markers of progression of HF, with lower rates of: 1) intensification of medical treatment for $\mathrm{HF}$ ( $16 \%$ risk reduction); 2) emergency department visits for worsening HF (34\% risk reduction); and 3) hospitalizations for worsening $\mathrm{HF}$ ( $23 \%$ fewer), need for intensive care (18\% rate reduction), need for intravenous inotropic agents (31\% risk reduction), and need for cardiac devices or heart transplants (22\% risk reduction). Besides, the patients also had lower rates of worsening symptom scores and elevation of biomarkers of myocardial injury. ${ }^{78}$ In relation to evaluation of subgroups, a brief description of the effects of sacubitril-valsartan association in these situations follows.
Age

Drug tolerance and outcomes in patients with HF vary by age. The prespecified efficacy and safety outcomes were examined in PARADIGM-HF according to age-group (years): $<55$ $(\mathrm{n}=1,624), 55-64(\mathrm{n}=2,655), 65-74 \quad(\mathrm{n}=2,557)$, and $\geq 75$ $(n=1,563)$. A larger number of patients with a broader range of ages were included in PARADIGM-HF than in any previous trial in HFrEF. The sacubitril-valsartan:enalapril hazard ratio was $<1$ in all categories, with an overall hazard ratio of $0.8(0.73,0.87 ; P<0.001)$. Although the rate of death and HF hospitalization increased with age in both groups, the sacubitril-valsartan association was more beneficial than enalapril across the broad spectrum of age and intolerance of association leading to treatment withdrawal was uncommon, even in elderly individuals. ${ }^{79}$ In addition, the enrolled population was in fact not very old (median age was 63.8 years).$^{80}$

\section{Ethnicity}

The majority of patients in PARADIGM-HF were white $(66 \%)$ or Asian $(18 \%)$. It is well known that black Americans have an increased risk of angioedema, ${ }^{81}$ but their presence in the PARADIGM-HF population was low $(\sim 5 \%)$. Therefore, it is difficult to draw definitive conclusions regarding the safety of this medication in this racial group. ${ }^{80}$

\section{Ejection fraction}

The influence of EF on clinical outcomes and the effectiveness of sacubitril-valsartan compared with enalapril was evaluated. The primary study end point was cardiovascular death or HF hospitalization. The mean left ventricular EF (LVEF) in PARADIGM-HF was 29.5 (interquartile range 25-34). The risk of all outcomes increased with decreasing LVEF. Each 5-point reduction in LVEF was associated with a 9\% increased risk of cardiovascular death or HF hospitalization and a 7\% increased risk in all-cause mortality in adjusted analyses. In this post hoc analysis of patients with HFrEF, LVEF was a powerful independent predictor of all outcomes. The sacubitril-valsartan association was effective at reducing cardiovascular outcomes and all-cause mortality across the LVEF spectrum, with no evidence of effect modification for any end point. ${ }^{82}$

\section{Biomarkers}

In patients with $\mathrm{HFrEF}$, BNP measurement contributes to better accuracy in diagnosis, reduces the rate of hospitalizations, and decreases mortality rates. ${ }^{83}$ Moreover, NP level represents a useful marker to monitor the course of the disease 
in relation to the benefits of therapeutic strategies. ${ }^{84}$ Therefore, the important clinical implications of NPs in HF indicate that NP-level measurement is one of the most effective tools for HF hormone-guided therapy. ${ }^{85}$ These clinical findings were confirmed by the effects on biomarkers measured in surviving patients in the trial. ${ }^{78}$ The levels of both urinary cyclic GMP and plasma BNP were higher during treatment with sacubitril-valsartan than with enalapril, ${ }^{78}$ which is expected when NEP inhibition occurs. ${ }^{86}$ In contrast, patients receiving LCZ696 had consistently lower levels of N-terminal (NT)proBNP (reflecting reduced cardiac wall stress) and troponin (reflecting reduced cardiac injury) compared to the enalapril group. As BNP (but not NT-proBNP) is a substrate for NEP, levels of BNP reflect the action of the drug, whereas levels of NT-proBNP reflect the effects of the drug on the heart. ${ }^{78,87}$

\section{Diabetes}

The patients of PARADIGM-HF were also examined according to history of diabetes mellitus and glycemic status (baseline $\mathrm{HbA}_{1 \mathrm{c}}<6 \%, 6 \%-6.4 \%$ [prediabetes], and $\geq 6.5 \%$ [diabetes mellitus]). Patients with a history of diabetes mellitus $(n=2,907$ [35\%]) had a higher risk of the primary composite outcome of HF hospitalization or cardiovascular mortality compared with those without a history of diabetes mellitus (adjusted hazard ratio 1.38, 95\% confidence interval $1.25-1.52 ; P<0.001)$. Patients with prediabetes were also at higher risk (hazard ratio $1.27,95 \%$ confidence interval 1.10-1.47; $P<0.001$ ) compared with those with $\mathrm{HbA}_{1 \mathrm{c}}<6 \%$. LCZ696 (sacubitril-valsartan) was beneficial compared with enalapril, irrespective of glycemic status. ${ }^{88}$

\section{Concerns in relation to sacubitril- valsartan}

Two potential long-term side effects and safety concerns related to the inhibition of neprilysin warrant consideration. Initially, there is evidence that NEP has protective activity against Alzheimer's disease by degrading the amyloid- $\beta(\mathrm{A} \beta)$ peptide. ${ }^{89}$ Inhibition of NEP in mice has resulted in increases in the levels of $A \beta$ and plaque-like deposits in the brain to levels that are 30-50 times higher than normal levels; these increases might lead to cognitive impairment. ${ }^{89}$ However, neprilysin is one of more than 20 enzymes that modulate the removal of $A \beta$ peptides, some of which are implicated in the pathogenesis of Alzheimer-type dementia. ${ }^{90}$ On the other hand, the results on this condition are controversial. Cognition-, memory-, and dementia-related adverse events did not increase in the LCZ696 group of the PARADIGM-HF trial. Therefore, NEP inhibition may block the breakdown of the key $A \beta$ peptide that has been implicated in the pathogenesis and progression of Alzheimer's disease. Cognitive function must be assessed during long-term treatment with sacubitril-valsartan, especially in elderly individuals. A trial of sacubitril-valsartan vs valsartan that includes repeated measurements of cognitive function in patients who have HF and preserved EF (HFpEF) is ongoing. ${ }^{91}$

Another concern about neprilysin and its inhibition is related to cancer. NEP seems to have a protector role in some kinds of cancer. Protection derives from the inactivation of mitogenic peptides, including endothelin 1 and bradykinin. NEP inhibits prostate cancer-cell invasion in vitro, ${ }^{92}$ and neprilysin overexpression has been associated with improved disease-free survival among women with breast cancer. ${ }^{93}$ However, in PARADIGM-HF no increase in the risk of cancer was associated with LCZ696. Moreover, 2-year carcinogenicity studies involving rodents that received the NEP inhibitor (sacubitril) component of LCZ696 did not show any increase in the incidence of tumors. Furthermore, there was no evidence of genotoxic potential in genetic toxicity studies of LCZ696, sacubitril, or the active metabolite LBQ657. 94

\section{Other uses for sacubitril-valsartan Hypertension}

In one of the first studies in the area of hypertension, Ruilope et al assessed 1,328 hypertensive subjects with uncomplicated mild-to-moderate essential hypertension to establish whether the dual actions of LCZ696 were superior to valsartan in lowering of blood pressure. ${ }^{95}$ Systolic, diastolic, and pulse pressures, both sitting and ambulatory, presented greater reductions with LCZ696 than with either valsartan or an NEP-inhibitor prodrug (AHU377) administered separately. The dual inhibition of the angiotensin II receptor and neprilysin was well tolerated at all doses, without excessive coughing and with no instances of angioedema, possibly because neprilysin is a minor enzyme in the metabolic pathway for bradykinin degradation. This shows that the dual inhibition provided by this drug has complementary effects, and suggests that the effects related to kinins from ACEIs are not needed for these beneficial effects. Similar findings were reported in an Asian population of hypertensive subjects. ${ }^{96}$

The safety of LCZ696 was also evaluated in 35 Japanese patients with severe hypertension (systolic blood pressure $\geq 180$ $\mathrm{mmHg}$ or diastolic blood pressure $\geq 110 \mathrm{mmHg}$ ), who initially received LCZ696 $200 \mathrm{mg}$. If necessary, the LCZ696 dose was increased to $400 \mathrm{mg}$ after 2 weeks followed by an optional addition of another antihypertensive drug (except ARBs or ACEIs) after 4 weeks $(n=21)$. There was clinically meaningful blood pressure reduction in patients with severe hypertension. The LCZ696-based regimen was well tolerated, and cases of 
angioedema were not registered..$^{97}$ The use of LCZ696 is justified, because it enhances NP levels and may be an attractive treatment option, particularly in Asian patients who generally have high salt sensitivity and salt intake.

\section{Heart failure with preserved ejection fraction}

Individuals with HFpEF were evaluated in the PARAMOUNT trial, which compared LCZ696 with valsartan. ${ }^{87}$ Compared to valsartan alone, the LCZ696 group had significantly lower NT-proBNP levels, and at 36 weeks decreased left atrial size and a trend toward improvements in New York Heart Association functional class. ${ }^{87}$ Another study to confirm the beneficial effects of dual inhibition in individuals with HFpEF, the PARAGON trial has begun. ${ }^{91}$ It intends to enroll 4,300 patients with LVEF $>45 \%$.

\section{Renal disease}

Blockade of the RAAS by either ACEIs or ARBs slows the progression of chronic kidney disease, with and without diabetes. ${ }^{98-100}$ The NEP inhibitor candoxatrilat has been shown to be associated with natriuresis in patients with moderate impairment of renal function. ${ }^{101}$ In trials with humans, omapatrilat was associated with greater slowing of renal function impairment than ACEIs. ${ }^{50,51}$ Similar findings were observed with ARNI (neprilysin-valsartan) in the PARADIGM-HF trial. ${ }^{29}$

These data suggest that neprilysin-valsartan may be superior to blockers of the RAAS in respect to renal function. Another study is comparing neprilysin-valsartan with the ARB irbesartan in subjects with renal disease and an estimated glomerular filtration rate between 20 and $60 \mathrm{~mL} / \mathrm{min} / 1.73 \mathrm{~m}^{2} .{ }^{102} \mathrm{As} \mathrm{HF}$ and renal dysfunction coexist, the question is whether ARNI might retard the development and/or progression of both conditions.

\section{Vascular stiffness}

In the elderly, vascular stiffness raises systolic blood pressure, pulse pressure, and pulse-wave velocity, which are independent predictors of cardiovascular events and of the progression of renal disease. ${ }^{103-105}$ In turn, noninvasively determined aortic blood pressure (central) is superior to brachial blood pressure (peripheral) in estimating cardiovascular risk. ${ }^{106,107}$ It is well known that central systolic blood pressure is a potent predictor of LV hypertrophy, whereas pulse pressure is a predictor of vascular hypertrophy. ${ }^{108}$ Omapatrilat presents a better response than enalapril in the reduction of both central and peripheral blood pressures, reflecting a reduction of vascular stiffness. This effect may be caused by the elevation of circulating ANP consequent to NEP inhibitors. ${ }^{49}$

LCZ696 also reduced both ambulatory systolic and pulse pressures more than valsartan. ${ }^{95}$ Further research could help to elucidate the role of the sacubitril-valsartan combination on vascular stiffness, and the PARAMETER study will compare LCZ696 with an ARB (olmesartan) in elderly hypertensive patients with a pulse pressure $>60 \mathrm{mmHg} .{ }^{109}$

\section{Mechanisms involved in the therapeutic answer to sacubitril-valsartan association in PARADIGM-HF}

When we compared the two RAAS blockers (ACEIs and ARBs) already standard in the treatment of HFrEF, with a new class of ARNI, we observed a significant additional reduction in cardiovascular mortality with ARNI (Figure 5). ${ }^{15,29,36,110}$ In summary, the effects of sacubitrilvalsartan on the NP system and RAAS in HF could explain the clinical benefits, but more studies will be necessary to investigate these findings. It seems unlikely that the benefits of sacubitril-valsartan are due to the valsartan component of the ARNI by itself, because the studies with ARBs were never superior to studies with ACEIs. ${ }^{36,110-113}$ The elevation of NP levels in the blood by itself does not seem to justify the benefits either, in view of the negative results

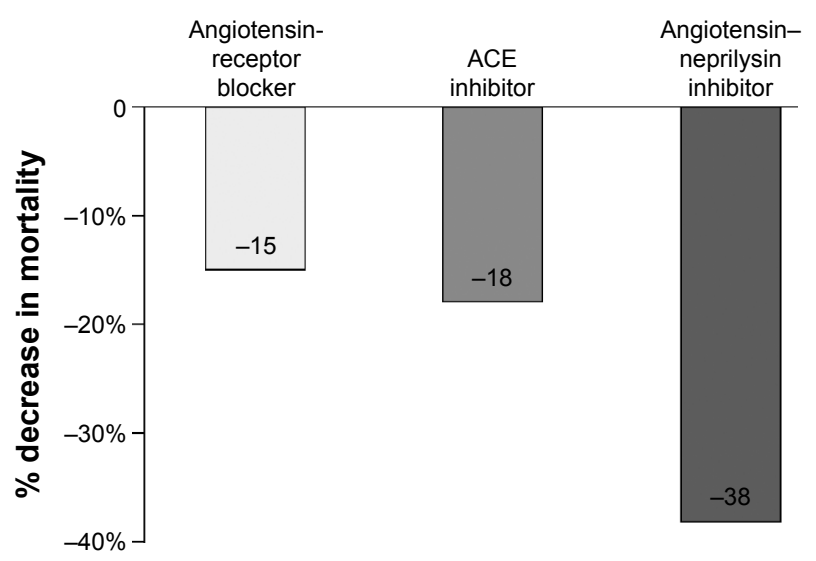

Figure 5 Additional benefit of an angiotensin-neprilysin inhibitor on cardiovascular death compared to an angiotensin-receptor blocker and an ACE inhibitor. Notes: The CHARM (candesartan in heart failure - assessment of mortality and morbidity) alternative trial compared an angiotensin-receptor blocker with placebo, ${ }^{110}$ the SOLVD (effect of enalapril on survival in patients with reduced left ventricular ejection fractions and congestive heart failure) treatment trial compared an ACE inhibitor with placebo, ${ }^{15}$ and the PARADIGM-HF (prospective comparison of ARNI with ACEI to determine impact on global mortality and morbidity in heart failure) trial compared an angiotensin-neprilysin inhibitor with an ACE inhibitor. ${ }^{29}$ Adapted with permission of Portland Press Ltd, from The natriuretic peptides system in the pathophysiology of heart failure: from molecular basis to treatment, Volpe M, Carnovali M, Mastromarino V, Clin Sci (Lond), 130(2), (c) 2016; permission conveyed through Copyright Clearance Center, Inc. ${ }^{36}$

Abbreviation: ACE, angiotensin-converting enzyme. 
on outcomes of previous studies with NEP inhibitors and vasopeptidase inhibitors, although a higher quantity of NPs can bind to receptors and produce the biological response. This possibility can be observed in a subpopulation of PARADIGM-HF, in which urinary cGMP was elevated in the group treated with sacubitril-valsartan. ${ }^{114}$ This can occur because NEP inhibitors augment the active NPs and consequently increase the generation of myocardial cGMP. On the other hand, the concomitant blockade of RAAS by the ARB (valsartan) may have partially antagonized the NPR-A downregulation, given the interactions between the angiotensin II and NP intracellular signaling pathways. ${ }^{36,115,116}$ Finally, two important roles can be attributed to the blood pressure-lowering effect of LCZ696 and the blockade of the $\mathrm{AT}_{1}$ receptor, which counteracts the increase in angiotensin II due to NEP inhibition.

\section{Conclusion}

The better clinical outcomes of the sacubitril-valsartan combination over enalapril in patients with HFrEF in the PARADIGM-HF trial represent a significant success with important clinical implications, despite all the doubts and concerns about this association. Although the results of PARADIGM-HF are noteworthy and promising, further research in other trials on HF and hypertension is necessary. It is important to ascertain how the drug will be tolerated when it is used in clinical practice.

\section{Disclosure}

The author reports no conflicts of interest in this work.

\section{References}

1. Mozaffarian D, Benjamin EJ, Go AS, et al. Heart disease and stroke statistics - 2016 update: a report from the American Heart Association. Circulation. 2016;133(4):e38-e360.

2. Ford ES, Ajani UA, Croft JB, et al. Explaining the decrease in U.S. deaths from coronary disease, 1980-2000. N Engl J Med. 2007;356(23): 2388-2398.

3. Lozano R, Naghavi M, Foreman K, et al. Global and regional mortality from 235 causes of death for 20 age groups in 1990 and 2010: a systematic analysis for the Global Burden of Disease Study 2010. Lancet. 2012;380(9859):2095-2128. Erratum in: Lancet. 2013;381(9867):628.

4. Moran AE, Forouzanfar MH, Roth GA, et al. The global burden of ischemic heart disease in 1990 and 2010: the Global Burden of Disease 2010 study. Circulation. 2014;129(14):1493-1501.

5. Nichols M, Townsend N, Scarborough P, Rayner M. Trends in agespecific coronary heart disease mortality in the European Union over three decades: 1980-2009. Eur Heart J. 2013;34(39):3017-3027.

6. Ambrosy AP, Fonarow GC, Butler J, et al. The global health and economic burden of hospitalizations for heart failure: lessons learned from hospitalized heart failure registries. $J$ Am Coll Cardiol. 2014;63(12): 1123-1133.

7. Heidenreich PA, Albert NM, Allen LA, et al. Forecasting the impact of heart failure in the United States: a policy statement from the American Heart Association. Circ Heart Fail. 2013;6(3):606-619.
8. Bahrami H, Kronmal R, Bluemke DA, et al. Differences in the incidence of congestive heart failure by ethnicity: the Multi-ethnic Study of Atherosclerosis. Arch Intern Med. 2008;168(19):2138-2145.

9. Braunwald E. The war against heart failure: the Lancet lecture. Lancet. 2015;385(9970):812-824.

10. Go AS, Mozaffarian D, Roger VL, et al. Heart disease and stroke statistics - 2014 update: a report from the American Heart Association. Circulation. 2014;129(3):e28-e292.

11. Vigen R, Maddox TM, Allen LA. Aging of the United States population: impact on heart failure. Curr Heart Fail Rep. 2012;9(4):369-374.

12. Dunlay SM, Redfield MM, Weston SA, et al. Hospitalizations after heart failure diagnosis: a community perspective. $J$ Am Coll Cardiol. 2009;54(18):1695-1702.

13. Ministério da Saúde. Information about morbidity: hospital admission. 2014. Available from: http://tabnet.datasus.gov.br/cgi/tabcgi.exe?sih/ cnv/niuf.def. Accessed December 24, 2015.

14. [No authors listed]. Effects of enalapril on mortality in severe congestive heart failure: results of the Cooperative North Scandinavian Enalapril Survival Study (CONSENSUS). N Engl J Med. 1987;316(23): 1429-1435.

15. [No authors listed]. Effect of enalapril on survival in patients with reduced left ventricular ejection fractions and congestive heart failure. N Engl J Med. 1991;325(5):293-302.

16. Pitt B, Zannad F, Remme WJ, et al. The effect of spironolactone on morbidity and mortality in patients with severe heart failure. $N$ Engl J Med. 1999;341(10):709-717.

17. McMurray JJ. CONSENSUS to EMPHASIS: the overwhelming evidence which makes blockade of the renin angiotensin aldosterone system the cornerstone of therapy for systolic heart failure. Eur J Heart Fail. 2011;13(9):929-936.

18. [No authors listed]. Effect of metoprolol CR/XL in chronic heart failure: Metoprolol CR/XL Randomised Intervention Trial in Congestive Heart Failure (MERIT-HF). Lancet. 1999;353(9169):2001-2007.

19. [No authors listed]. The Cardiac Insufficiency Bisoprolol Study II (CIBIS-II): a randomised trial. Lancet. 1999;353(9146):9-13.

20. Packer M, Coats AJ, Fowler MB, et al. Effect of carvedilol on survival in severe chronic heart failure. N Engl J Med. 2001;344(22): $1651-1658$

21. Shibata MC, Flather MD, Wang D. Systematic review of the impact of beta blockers on mortality and hospital admissions in heart failure. Eur J Heart Fail. 2001;3(3):351-357.

22. Levy D, Kenchaiah S, Larson MG, et al. Long-term trends in the incidence of and survival with heart failure. $N$ Engl J Med. 2002;347(18): $1397-1402$.

23. Roger VL, Weston SA, Redfield MM, et al. Trends in heart failure incidence and survival in a community-based population. JAMA. 2004; 292(3):344-350.

24. Barker WH, Mullooly JP, Getchell W. Changing incidence and survival for heart failure in a well-defined older population, 1970-1974 and 1990-1994. Circulation. 2006;113(6):799-805.

25. Fonarow GC, Abraham WT, Albert NM, et al. Factors identified as precipitating hospital admissions for heart failure and clinical outcomes: findings from OPTIMIZE-HF. Arch Intern Med. 2008;168(8): 847-854.

26. Guha K, McDonagh T. Heart failure epidemiology: European perspective. Curr Cardiol Rev. 2013;9(2):123-127.

27. Roger VL. Epidemiology of heart failure. Circ Res. 2013;113(6): 646-659.

28. Yusuf S, Rangarajan S, Teo K, et al. Cardiovascular risk and events in 17 low-, middle-, and high-income countries. $N$ Engl J Med. 2014;371(9):818-827.

29. McMurray JJ, Packer M, Desai AS, et al. Angiotensin-neprilysin inhibition versus enalapril in heart failure. $N$ Engl J Med. 2014;371(11): 993-1004.

30. Levin ER, Gardner DG, Samson WK. Natriuretic peptides. $N$ Engl J Med. 1998;339(5):321-328.

31. Baxter GF. The natriuretic peptides. Basic Res Cardiol. 2004;99(2): 71-75. 
32. Pandey KN. Biology of natriuretic peptides and their receptors. Peptides. 2005;26(6):901-932.

33. Volpe M. Natriuretic peptides and cardio-renal disease. Int J Cardiol. 2014;176(3):630-639.

34. Potter LR, Abbey-Hosch S, Dickey DM. Natriuretic peptides, their receptors, and cyclic guanosine monophosphate-dependent signaling functions. Endocr Rev. 2006;27(1):47-72.

35. Rubattu S, Sciarretta S, Valenti V, Stanzione R, Volpe M. Natriuretic peptides: an update on bioactivity, potential therapeutic use, and implication in cardiovascular diseases. Am J Hypertens. 2008;21(7): 733-741.

36. Volpe M, Carnovali M, Mastromarino V. The natriuretic peptides system in the pathophysiology of heart failure: from molecular basis to treatment. Clin Sci (Lond). 2016;130(2):57-77.

37. Sonnenberg JL, Sakane Y, Jeng AY, et al. Identification of protease 3.4.24.11 as the major atrial natriuretic factor degrading enzyme in the rat kidney. Peptides. 1988;9(1):173-180.

38. Segura J, Ruilope LM. Dual-acting angiotensin receptor-neprilysin inhibition. Curr Hypertens Rep. 2011;13(1):74-78.

39. Bevan EG, Connell JM, Doyle J, et al. Candoxatril, a neutral endopeptidase inhibitor: efficacy and tolerability in essential hypertension. J Hypertens. 1992;10(7):607-613.

40. Richards AM, Wittert GA, Crozier IG, et al. Chronic inhibition of endopeptidase 24.11 in essential hypertension: evidence for enhanced atrial natriuretic peptide and angiotensin II. J Hypertens. 1993;11(4): 407-416.

41. McDowell G, Coutie W, Shaw C, Buchanan KD, Struthers AD, Nicholls DP. The effect of the neutral endopeptidase inhibitor drug, candoxatril, on circulating levels of two of the most potent vasoactive peptides. Br J Clin Pharmacol. 1997;43(3):329-332.

42. Ferro CJ, Spratt JC, Haynes WG, Webb DJ. Inhibition of neutral endopeptidase causes vasoconstriction of human resistance vessels in vivo. Circulation. 1998;97(23):2323-2330.

43. Ando S, Rahman MA, Butler GC, Senn BL, Floras JS. Comparison of candoxatril and atrial natriuretic factor in healthy men: effects on hemodynamics, sympathetic activity, heart rate variability, and endothelin. Hypertension. 1995;26(6 Pt 2):1160-1166.

44. Cleland JG, Swedberg K. Lack of efficacy of neutral endopeptidase inhibitor ecadotril in heart failure. Lancet. 1998;351(9116):1657-1658.

45. Burnett JC Jr. Vasopeptidase inhibition: a new concept in blood pressure management. J Hypertens. 1999; 17 Suppl 1:S37-S43.

46. Robl JA, Sun CQ, Stevenson J, et al. Dual metalloprotease inhibitors: mercaptoacetyl-based fused heterocyclic dipeptide mimetics as inhibitors of angiotensin-converting enzyme and neutral endopeptidase. $J \mathrm{Med}$ Chem. 1997;40(11):1570-1577.

47. Trippodo NC, Robl JA, Asaad MM, Fox M, Panchal BC, Schaeffer TR. Effects of omapatrilat in low, normal, and high renin experimental hypertension. Am J Hypertens. 1998;11(3 Pt 1):363-372.

48. Liao WC, Vesterqvist O, Delaney C, et al. Pharmacokinetics and pharmacodynamics of the vasopeptidase inhibitor, omapatrilat in healthy subjects. Br J Clin Pharmacol. 2003;56(4):395-406.

49. Mitchell GF, Izzo JL Jr, Lacourcière Y, et al. Omapatrilat reduces pulse pressure and proximal aortic stiffness in patients with systolic hypertension: results of the Conduit Hemodynamics of Omapatrilat International Research Study. Circulation. 2002;105(25):2955-2961.

50. Rouleau JL, Pfeffer MA, Stewart DJ, et al. Comparison of vasopeptidase inhibitor, omapatrilat, and lisinopril on exercise tolerance and morbidity in patients with heart failure: IMPRESS randomised trial. Lancet. 2000; 356(9230):615-620.

51. Packer M, Califf RM, Konstam MA, et al. Comparison of omapatrilat and enalapril in patients with chronic heart failure: the Omapatrilat Versus Enalapril Randomized Trial of Utility in Reducing Events (OVERTURE). Circulation. 2002;106(8):920-926.

52. Kostis JB, Packer M, Black HR, Schmieder R, Henry D, Levy E. Omapatrilat and enalapril in patients with hypertension: the Omapatrilat Cardiovascular Treatment vs. Enalapril (OCTAVE) trial. Am J Hypertens. 2004;17(2):103-111.
53. Fryer RM, Segreti J, Banfor PN, et al. Effect of bradykinin metabolism inhibitors on evoked hypotension in rats: rank efficacy of enzymes associated with bradykinin-mediated angioedema. Br J Pharmacol. 2008;153(5):947-955.

54. Blumberg AL, Denny SE, Marshall GR, Needleman P. Blood vesselhormone interactions: angiotensin, bradykinin, and prostaglandins. Am J Physiol. 1977;232(3):H305-H310.

55. Campbell DJ. Vasopeptidase inhibition: a double-edged sword? Hypertension. 2003;41(3):383-389.

56. Braunwald $\mathrm{E}$. The path to an angiotensin receptor antagonist-neprilysin inhibitor in the treatment of heart failure. J Am Coll Cardiol. 2015;65(10): 1029-1041.

57. Gu J, Noe A, Chandra P, Al-Fayoumi S, Ligueros-Saylan M. Pharmacokinetics and pharmacodynamics of LCZ696, a novel dual-acting angiotensin receptor-neprilysin inhibitor(ARNi). J Clin Pharmacol. 2010;50(4):401-414.

58. Hegde LG, Yu C, Renner T, et al. Concomitant angiotensin AT1 receptor antagonism and neprilysin inhibition produces omapatrilat-like antihypertensive effects without promoting tracheal plasma extravasation in the rat. J Cardiovasc Pharmacol. 2011;57(4):495-504.

59. Cicardi M, Zingale LC, Bergamaschini L, Agostoni A. Angioedema associated with angiotensin-converting enzyme inhibitor use: outcome after switching to a different treatment. Arch Intern Med. 2004;164(8): 910-913.

60. Mistry NB, Westheim AS, Kjeldsen SE. The angiotensin receptor antagonist valsartan: a review of the literature with a focus on clinical trials. Expert Opin Pharmacother. 2006;7(5):575-581.

61. Ksander GM, Ghai RD, de Jesus R, et al. Dicarboxylic acid dipeptide neutral endopeptidase inhibitors. J Med Chem. 1995;38(10):1689-1700.

62. Rademaker MT, Charles CJ, Espiner EA, Nicholls MG, Richards AM, Kosoglou T. Combined neutral endopeptidase and angiotensin-converting enzyme inhibition in heart failure: role of natriuretic peptides and angiotensin II. J Cardiovasc Pharmacol. 1998;31(1):116-125.

63. McMurray JJ, Adamopoulos S, Anker SD, et al. ESC guidelines for the diagnosis and treatment of acute and chronic heart failure 2012: the Task Force for the Diagnosis and Treatment of Acute and Chronic Heart Failure 2012 of the European Society of Cardiology. Developed in collaboration with the Heart Failure Association (HFA) of the ESC. Eur Heart J. 2012;33(14):1787-1847.

64. Yancy CW, Jessup M, Bozkurt B, et al. 2013 ACCF/AHA guideline for the management of heart failure: a report of the American College of Cardiology Foundation/American Heart Association Task Force on Practice Guidelines. J Am Coll Cardiol. 2013;62(16):e147-e239.

65. Jessup M. Neprilysin inhibition - a novel therapy for heart failure. N Engl J Med. 2014;371(11):1062-1064.

66. Lewington S, Clarke R, Qizilbash N, Peto R, Collins R. Age-specific relevance of usual blood pressure to vascular mortality: a meta-analysis of individual data for one million adults in 61 prospective studies. Lancet. 2002;360(9349):1903-1913.

67. Blankfield RP. To the editor: the PARADIGM-HF trial. Cleve Clin J Med. 2016;83(3):167.

68. [No authors listed]. Effect of enalapril on mortality and the development of heart failure in asymptomatic patients with reduced left ventricular ejection fractions. N Engl J Med. 1992;327(10):685-691.

69. Cohn JN, Johnson G, Ziesche S, et al. A comparison of enalapril with hydralazine-isosorbide dinitrate in the treatment of chronic congestive heart failure. $N$ Engl J Med. 1991;325(5):303-310.

70. [No authors listed]. Clinical outcome with enalapril in symptomatic chronic heart failure; a dose comparison: the NETWORK investigators. Eur Heart J. 1998;19(3):481-489.

71. Nanas JN, Alexopoulos G, Anastasiou-Nana MI, et al. Outcome of patients with congestive heart failure treated with standard versus high doses of enalapril: a multicenter study. J Am Coll Cardiol. 2000;36(7): 2090-2095.

72. Komajda M, Lutiger B, Madeira H, et al. Tolerability of carvedilol and ACE-inhibition in mild heart failure: results of CARMEN (Carvedilol ACE-Inhibitor Remodelling Mild CHF EvaluatioN). Eur J Heart Fail. 2004;6(4):467-475. 
73. Messner Pellenc P, Rudnicki A, Leclercq F, Grolleau R. Enalapril in the treatment of mild-to-moderate heart failure in general medical practice: a prospective and multicentre study concerning 17,546 patients. Acta Cardiol. 1995;50(3):187-201.

74. McMurray JJ, Packer M, Desai AS, et al. Dual angiotensin receptor and neprilysin inhibition as an alternative to angiotensin-converting enzyme inhibition in patients with chronic systolic heart failure: rationale for and design of the Prospective Comparison of ARNI with ACEI to Determine Impact on Global Mortality and Morbidity in Heart Failure trial (PARADIGM-HF). Eur J Heart Fail. 2013;15(9):1062-1073.

75. Sabe MA, Jacob MS, Taylor DO. In reply: the PARADIGM-HF trial. Cleve Clin J Med. 2016;83(3):167-168.

76. Correia LC, Rassi A Jr. Paradigm-HF: a paradigm shift in heart failure treatment? Arq Bras Cardiol. 2016;106(1):77-79.

77. Sabe MA, Jacob MS, Taylor DO. A new class of drugs for systolic heart failure: the PARADIGM-HF study. Cleve Clin J Med. 2015;82(10): 693-701.

78. Packer M, McMurray JJV, Desai AS, et al. Angiotensin receptor neprilysin inhibition compared with enalapril on the risk of clinical progression in surviving patients with heart failure. Circulation. 2015; 131(1):54-61.

79. Jhund PS, Fu M, Bayram E, et al. Efficacy and safety of LCZ696 (sacubitril-valsartan) according to age: insights from PARADIGM-HF. Eur Heart J. 2015;36(38):2576-2584.

80. Kaplinsky E. PARADIGM-HF trial: will LCZ696 change the current treatment of systolic heart failure? J Geriatr Cardiol. 2015;12(5): 470-473.

81. Brown NJ, Ray WA, Snowden M, Griffin MR. Black Americans have an increased rate of angiotensin converting enzyme inhibitor-associated angioedema. Clin Pharmacol Ther. 1996;60(1):8-13.

82. Solomon SD, Claggett B, Desai AS, et al. Influence of ejection fraction on outcomes and efficacy of sacubitril/valsartan (LCZ696) in heart failure with reduced ejection fraction: the Prospective Comparison of ARNI with ACEI to Determine Impact on Global Mortality and Morbidity in Heart Failure (PARADIGM-HF) trial. Circ Heart Fail. 2016;9(3):e002744.

83. Bhardwaj A, Januzzi JL Jr. Natriuretic peptide-guided management of acutely destabilized heart failure: rationale and treatment algorithm. Crit Pathw Cardiol. 2009;8(4):146-150.

84. Motiwala SR, Januzzi JL Jr. The role of natriuretic peptides as biomarkers for guiding the management of chronic heart failure. Clin Pharmacol Ther. 2013;93(1):57-67.

85. Volpe M, Rubattu M, Burnett J Jr. Natriuretic peptides in cardiovascular diseases: current use and perspectives. Eur Heart J. 2014;35(7): 419-425.

86. Charles CJ, Espiner EA, Nicholls MG, et al. Clearance receptors and endopeptidase 24.11: equal role in natriuretic peptide metabolism in conscious sheep. Am J Physiol. 1996;271(2 Pt 2):R373-R380.

87. Solomon SD, Zile M, Pieske B, et al. The angiotensin receptor neprilysin inhibitor LCZ696 in heart failure with preserved ejection fraction: a phase 2 double-blind randomised controlled trial. Lancet. 2012;380(9851):1387-1395.

88. Kristensen SL, Preiss D, Jhund PS, et al. Risk related to pre-diabetes mellitus and diabetes mellitus in heart failure with reduced ejection fraction: insights from Prospective Comparison of ARNI with ACEI to Determine Impact on Global Mortality and Morbidity in Heart Failure trial. Circ Heart Fail. 2016;9(1):e002560.

89. Miners JS, Barua N, Kehoe PG, Gill S, Love S. A $\beta$-degrading enzymes: potential for treatment of Alzheimer disease. J Neuropathol Exp Neurol. 2011;70(11):944-959.

90. Nalivaeva NN, Belyaev ND, Kerridge C, Turner AJ. Amyloid-clearing proteins and their epigenetic regulation as a therapeutic target in Alzheimer's disease. Front Aging Neurosci. 2014;6:235.

91. Novartis Pharmaceuticals. Efficacy and Safety of LCZ696 Compared to Valsartan, on Morbidity and Mortality in Heart Failure Patients with Preserved Ejection Fraction (PARAGON-HF). Available from: https:/clinicaltrials.gov/ct2/show/NCT01920711. NLM identifier: NCT01920711. Accessed January 4, 2016.
92. Dawson LA, Maitland NJ, Turner AJ, Usmani BA. Stromal-epithelial interactions influence prostate cancer cell invasion by altering the balance of metallopeptidase expression. Br J Cancer. 2004;90(8): 1577-1582.

93. Smollich M, Götte M, Yip GW, et al. On the role of endothelinconverting enzyme-1 (ECE-1) and neprilysin in human breast cancer. Breast Cancer Res Treat. 2007;106(3):361-369.

94. Center for Drug Evaluation and Research. Application number: 207620orig1s000 - summary review. 2015. Available from: http://www. accessdata.fda.gov/drugsatfda_docs/nda/2015/207620Orig1s000SumR. pdf. Accessed January 4, 2016.

95. Ruilope LM, Dukat A, Böhm M, Lacourcière Y, Gong J, Lefkowitz MP. Blood-pressure reduction with LCZ696, a novel dual-acting inhibitor of the angiotensin II receptor and neprilysin: a randomised, double-blind, placebo-controlled, active comparator study. Lancet. 2010;375(9722):1255-1266.

96. Kario K, Sun N, Chiang FT, et al. Efficacy and safety of LCZ696, a first-in-class angiotensin receptor neprilysin inhibitor, in Asian patients with hypertension: a randomized, double-blind, placebocontrolled study. Hypertension. 2014;63(4):698-705.

97. Kario K, Tamaki Y, Okino N, Gotou H, Zhu M, Zhang J. LCZ696, a first-in-class angiotensin receptor-neprilysin inhibitor: the first clinical experience in patients with severe hypertension. J Clin Hypertens (Greenwich). 2016;18(4):308-314.

98. Lewis EJ, Hunsicker LG, Bain RP. The effect of angiotensin-convertingenzyme inhibition on diabetic nephropathy. N Engl J Med. 1993; 329(20):1456-1462.

99. Ruggenenti P, Perna A, Gherardi G, et al. Renoprotective properties of ACE-inhibition in non-diabetic nephropathies with non-nephrotic proteinuria. Lancet. 1999;354(9176):359-364.

100. Brenner BM, Cooper ME, de Zeeuw D, et al. Effects of losartan on renal and cardiovascular outcomes in patients with type 2 diabetes and nephropathy. N Engl J Med. 2001;345(12):861-869.

101. Lipkin GW, Dawnay AB, Harwood SM, Cattell WR, Raine AE. Enhanced natriuretic response to neutral endopeptidase inhibition in patients with moderate chronic renal failure. Kidney Int. 1997; 52(3):792-801.

102. Judge P, Haynes R, Landray MJ, Baigent C. Neprilysin inhibition in chronic kidney disease. Nephrol Dial Transplant. 2015;30(5):738-743.

103. Mattace-Raso FU, van der Cammen TJ, Hofman A, et al. Arterial stiffness and risk of coronary heart disease and stroke: the Rotterdam Study. Circulation. 2006;113(5):657-663.

104. Weber T, Auer J, O’Rourke MF, et al. Arterial stiffness, wave reflections, and the risk of coronary artery disease. Circulation. 2004;109(2): 184-189.

105. Ford ML, Tomlinson LA, Chapman TP, Rajkumar C, Holt SG. Aortic stiffness is independently associated with rate of renal function decline in chronic kidney disease stages 3 and 4. Hypertension. 2010; 55(5):1110-1115.

106. Roman MJ, Devereux RB, Kizer JR, et al. Central pressure more strongly relates to vascular disease and outcome than does brachial pressure: the Strong Heart Study. Hypertension. 2007;50(1):197-203.

107. Booysen HL, Norton GR, Maseko MJ, et al. Aortic, but not brachial blood pressure category enhances the ability to identify target organ changes in normotensives. J Hypertens. 2013;31(6):1124-1130.

108. Roman MJ, Okin PM, Kizer JR, Lee ET, Howard BV, Devereux RB. Relations of central and brachial blood pressure to left ventricular hypertrophy and geometry: the Strong Heart Study. J Hypertens. 2010;28(2):384-388.

109. Williams B, Cockcroft JR, Kario K, et al. Rationale and study design of the Prospective Comparison of Angiotensin Receptor Neprilysin Inhibitor with Angiotensin Receptor Blocker Measuring Arterial Stiffness in the Elderly (PARAMETER) study. BMJ Open. 2014;4(2):e004254.

110. Young JB, Dunlap ME, Pfeffer MA, et al. Mortality and morbidity reduction with Candesartan in patients with chronic heart failure and left ventricular systolic dysfunction: results of the CHARM lowleft ventricular ejection fraction trials. Circulation. 2004;110(17): 2618-2626. 
111. Pitt B, Segal R, Martinez FA, et al. Randomised trial of losartan versus captopril in patients over 65 with heart failure (Evaluation of Losartan in the Elderly study, ELITE). Lancet. 1997;349(9054):747-752.

112. Pfeffer MA, McMurray JJ, Velazquez EJ, et al. Valsartan, captopril, or both in myocardial infarction complicated by heart failure, left ventricular dysfunction, or both. N Engl J Med. 2003;349(20):1893-1906.

113. Cohn JN, Tognoni G. A randomized trial of the angiotensin-receptor blocker valsartan in chronic heart failure. N Engl J Med. 2001;345(23): 1667-1675.

114. Klaiber M, Kruse M, Völker K, et al. Novel insights into the mechanisms mediating the local antihypertrophic effects of cardiac atrial natriuretic peptide: role of cGMP-dependent protein kinase and RGS2. Basic Res Cardiol. 2010;105(5):583-595.
115. Kim D, Aizawa T, Wei H, et al. Angiotensin II increases phosphodiesterase 5A expression in vascular smooth muscle cells: a mechanism by which angiotensin II antagonizes cGMP signaling. J Mol Cell Cardiol. 2005;38(1):175-184.

116. Frantz S, Klaiber M, Baba HA, et al. Stress-dependent dilated cardiomyopathy in mice with cardiomyocyte-restricted inactivation of cyclic GMP-dependent protein kinase I. Eur Heart J. 2013; 34(16):1233-1244

\section{Publish your work in this journal}

Drug Design, Development and Therapy is an international, peerreviewed open-access journal that spans the spectrum of drug design and development through to clinical applications. Clinical outcomes, patient safety, and programs for the development and effective, safe, and sustained use of medicines are a feature of the journal, which has also been accepted for indexing on PubMed Central. The manuscript management system is completely online and includes a very quick and fair peer-review system, which is all easy to use. Visit http://www.dovepress.com/testimonials.php to read real quotes from published authors.

Submit your manuscript here: http://www.dovepress.com/drug-design-development-and-therapy-journal 